\title{
Studies on the role of homobrassinolide on the metabolites in turmeric leaves
}

\author{
G Rajesh and B Vidya Vardhini* \\ Department of Botany, Telangana University, Dichpally, Nizamabad -503322, India.
}

Magna Scientia Advanced Research and Reviews, 2021, 01(03), 030-034

Publication history: Received on 27 January 2021; revised on 26 February 2021; accepted on 01 March 2021

Article DOI: https://doi.org/10.30574/msarr.2021.1.3.0022

\begin{abstract}
The effect of homobrassinolide (HBL) sprayed in four different concentrations viz., viz., $0.5 \mu \mathrm{M}, 1.0 \mu \mathrm{M}, 2.0 \mu \mathrm{M}$, and 3.0 $\mu \mathrm{M}$ on the metabolites viz., chlorophyll pigments, carbohydrate fractions (reducing sugars, non-reducing sugars, total sugars and starch) and soluble proteins present in turmeric plants grown in the semi-arid tropics of Nizamabad was studied. The soil of Nizamabad is known to posses high concentrations of salt and the place is usually a semi-arid tropical area where the crops are prone to drought and salt stresses and foliar application of HBL is to ameliorate these stresses and improve the metabolites of turmeric plant. All the four concentrations of HBL played a very positive role in ameliorating the saline stress and enhanced the metabolite contents viz., chlorophyll pigments, carbohydrate fractions (reducing sugars, total sugars, total sugars and starch), and soluble proteins in turmeric plants. HBL at 3.0 $\mu \mathrm{M}$ was found most effective in increasing chlorophyll pigments, carbohydrates and soluble proteins compared to the other treatments as well as control plants.
\end{abstract}

Keywords: Homobrassinolide (HBL); Carbohydrates; Chlorophyll pigments; Soluble proteins

\section{Introduction}

Plant Growth Regulators (PGRs) organize and help in adjustment of the physiological, atomic and biochemical instruments to build pressure resilience for development and improvement in crop plants [1, 2] and among the recently included PGRs, BRs have been the subject of sharp enthusiasm for plant scientists for their role in growth and metabolism of plants under normal as well as stressful environment. Brassinosteroids (BRs) are fundamental low molecular weight PGRs (plant growth regulators) that are omnipresent all through the plant kingdom [3] and were first reported by Mitchell et al. [4] in 'Nature' depicting the growth promoting activity of Brassica napus L. pollen extricates at very low amounts. The cascades of research on these potential PGRs is gaining much importance and the research studies on BRs clearly depict their ability to mitigate various biotic (bacteria, virus, fungi, nematodes) and abiotic (temperature, salt, drought, metal, water) in plants $[5,6,7$,$] .$

Turmeric (Curcuma longa L.) plant belongs to ginger family (Zingiberaceae). It is an established fact that turmeric plant is often called as a 'wonder spice' capable of acting as an antioxidant and used in all parts of India in most of the dishes. Curcuma longa L. is sterile as is incapable of producing seeds. Hence it is widely propagated from its rhizomes. The present research study is undertaken to give an insight on the application of homobrassinolide (HBL) on metabolites viz., chlorophyll pigments, carbohydrate fractions (reducing sugars, non-reducing sugars, total sugars and starch) and soluble proteins present in turmeric plants grown in the semi-arid tropics of Nizamabad.

\footnotetext{
${ }^{*}$ Corresponding author: B Vidya Vardhini

Department of Botany, Telangana University, Dichpally, Nizamabad -503322, India.
} 


\section{Material and methods}

Curcuma longa L. plant popularly called as 'turmeric' plant belongs to the ginger family (Zingiberaceae) is the present research study material. The underground rhizomes of Curcuma longa L. variety Acc-79 were purchased from Ashwini Fertilizers Ltd., Nizamabad. Homobrassinolide (HBL) was procured from Godrej Agrovet Pvt. Ltd., Hyderabad, Telangana State, India. Homobrassinolide obtained as Double comprises of $0.04 \%$ of Homobrassinolide, $4.0 \%$ of water and solvent.

Curcuma longa L. plants were grown under natural day length in Nizamabad district of Telangana State, India. The experiments were conducted in the field plots beds. Each plot bed consisted of 121 square yards in measurement. A total of 5 plot beds were prepared resulting in 605 (121 x 5) square yards of total field sizes. The distance between each bed was around two and a half feet. Care was taken to maintain 1/2 feet distance between each plant. The selected plots were mixed with manure and vermi compost. The rhizomes were sterilized by metaloxin mangozeb $(250 \mathrm{~g} / 250 \mathrm{ml}$ concentration) by soaking for 30 minutes. After 30 minutes, the turmeric rhizomes were dried in shade for around one and a half hour and planted in the plots mentioned above. After 15 days of sowing, the saplings were exogenously treated with $70 \%$ thiophanate methyl which is a fungicide.

The turmeric plants were grown in the field conditions in the semi-arid tropics of Nizamabad. Homobrassinolide was supplied as foliar spray where four different concentrations viz., $0.5 \mu \mathrm{M}, 1.0 \mu \mathrm{M}, 2.0 \mu \mathrm{M}$, and $3.0 \mu \mathrm{M}$ were taken based on the experimental studies conducted by Vardhini and Rao $[8,9]$. Ten plants were chosen for foliar application of each concentration. The first homobrassinolide spray was given as foliar spray when the turmeric plants were twenty - day old. Homobrassinolide was exogenously applied as foliar spray three times to the turmeric plants viz., on the 20th, 40 th and 60th day from sowing. The control turmeric plants were treated with distilled water on the same days. Fresh turmeric leaves were used for analysis of chlorophylls on the 25th day and 45th day. The turmeric leaves were fixed in $70 \%(\mathrm{v} / \mathrm{v})$ ethyl alcohol on the 65th day from planting rhizomes after taking all the necessary precautions. The ethanol homogenate was used for the analysis of carbohydrates and soluble proteins.

\subsection{Chlorophyll pigments}

Chlorophyll pigments were extracted and estimated by the procedure described by Arnon [10]. Leaves were homogenized with $80 \%(\mathrm{v} / \mathrm{v})$ acetone and centrifuged. The acetone extract was used to calculate the chlorophyll $\mathrm{a}, \mathrm{b}$ and total chlorophylls employing the formula given below.

Chlorophylls 'a' $=[$ O.D at $663 \times 12.7-0 . D$ at $645 \times 2.69] \times[v / 1000) \times w]$

Chlorophyll 'b' $=[$ O.D at $645 \times 22.9-$ O.D. at $663 \times 4.68] \times[v / 1000) \times w]$

Total chlorophylls $=[$ O.D at $663 \times 8.2+0 . D$ at $645 \times 20.2] \times[v / 1000) \times w]$ Where: $v=$ volume of acetone extract, $\mathrm{w}=$ weight of leaves.

\subsection{Carbohydrate fractions}

The alcohol homogenate was heated and centrifuged. The centrifuge tube was kept in a boiling water bath for five minutes. The contents were cooled to room temperature. The contents were centrifuged at 4,000 rpm in a Remi-T-8 centrifuge. The residue was re-extracted with $5 \mathrm{ml}$ of $70 \%(\mathrm{~V} / \mathrm{V})$ ethyl alcohol and was re-centrifuged for 10 minutes. This procedure was repeated three times. The ethyl alcohol supernatants were poured into a $25 \mathrm{ml}$ test tube and the volume was made up to $10 \mathrm{ml}$ with $70 \%(\mathrm{~V} / \mathrm{V})$ ethyl alcohol which was used for the determination of reducing [11], nonreducing [12] and total sugars [13] present in turmeric leaves. The residue obtained was used for the determination of starch [14].

\subsection{Soluble proteins}

Soluble proteins in the ethanol homogenate were precipitated by adding $20 \%(\mathrm{w} / \mathrm{v})$ tricholoroacetic acid. The precipitate was dissolved in $1 \%(\mathrm{w} / \mathrm{v})$ sodium hydroxide. The method of Lowry et al. [15] was used for protein estimation.

\section{Results}

All the four concentrations of homobrassinolide (HBL) increased the total chlorophylls content of turmeric leaves as compared to untreated control leaves of turmeric (Table 1). 3.0 $\mu \mathrm{M}$ HBL was found to be most effective in enhancing 
the chlorophyll levels of turmeric plant. Substantial increase in chlorophyll ' $a$ ' and chlorophyll ' $b$ ' was also observed in plants treated with $3.0 \mu \mathrm{M}$ HBL concentration and caused an improvement around $61.19 \%$ in chlorophyll 'a' and around $41.98 \%$ increment in chlorophyll 'b' contents. Similarly 0.5 $\mu$ M HBL, $1.0 \mu$ M HBL and $2.0 \mu$ M HBL concentrations also accounted for good increases in chlorophyll ' $a$ ' and chlorophyll ' $b$ ' contents of turmeric leaves.

Exogenous application of HBL to turmeric plants improved the carbohydrate pools gradually by increasing the concentrations from $0.5 \mu \mathrm{M}, 1.0 \mu \mathrm{M}, 2.0 \mu \mathrm{M}$ and $3.0 \mu \mathrm{M}$ HBL respectively. All the supplied four different concentrations of HBL significantly increased the reducing sugars in the turmeric leaves (Table 2). The levels of reducing sugars increased around $69.23 \%$ for $0.5 \mu \mathrm{M} \mathrm{HBL}, 100.31 \%$ for $1.0 \mu \mathrm{M} \mathrm{HBL}, 200.16 \%$ for $2.0 \mu \mathrm{M}$ HBL and $200.70 \%$ for $3.0 \mu \mathrm{M} \mathrm{HBL}$ treatments compared with controls.

The exogenous application of all the four different concentrations of HBL viz., $0.5 \mu \mathrm{M}$ HBL, 1.0 $\mu \mathrm{M}$ HBL, $2.0 \mu \mathrm{M}$ HBL and 3.0 $\mu \mathrm{M}$ HBL resulted in marked increment of non-reducing sugars in leaves of turmeric plants grown in Nizamabad district. The results of the non -reducing sugars of HBL treated as well as control turmeric plants are shown in Table 2. The levels of non-reducing sugars for $0.5 \mu \mathrm{M}$ treated HBL increased to $100.3 \%$, for $1.0 \mu \mathrm{M}$ treated HBL it increased to $100.42 \%$, for $2.0 \mu \mathrm{M}$ treated $\mathrm{HBL}$ it increased to $100.98 \%$ and for $3.0 \mu \mathrm{M}$ treated HBL it increased to $200.19 \%$ compared to untreated controls.

Foliar spraying of four concentrations of HBL $(0.5 \mu \mathrm{M}, 1.0 \mu \mathrm{M}, 2.0 \mu \mathrm{M}$ and $3.0 \mu \mathrm{M})$ exhibited in enhanced levels of total sugars in turmeric leaves. The increased levels of total sugars compared to the untreated controls are presented in Table 2. The levels of total sugars for $0.5 \mu \mathrm{M}$ treated HBL increased to $36.53 \%$, for $1.0 \mu \mathrm{M}$ treated HBL increased to $80.08 \%$, for $2.0 \mu \mathrm{M}$ treated $\mathrm{HBL}$ increased to $100.25 \%$ and for $3.0 \mu \mathrm{M}$ treated HBL increased to $100.69 \%$ when compared with control plants.

Foliar supplementation of HBL as $0.5 \mu \mathrm{M}, 1.0 \mu \mathrm{M}, 2.0 \mu \mathrm{M}$ and $3.0 \mu \mathrm{M}$ concentrations exhibited in increased levels of starch content in turmeric leaves. The increased levels of starch contents compared to the untreated controls are presented in Table 2. The levels of starch for $0.5 \mu \mathrm{M}$ HBL increased to $6.53 \%$, for $1.0 \mu \mathrm{M}$ HBL increased to $12.01 \%$, for $2.0 \mu \mathrm{M}$ HBL increased to $21.20 \%$ and for $3.0 \mu \mathrm{M}$ HBL increased to $32.14 \%$ when compared with control plants.

The results obtained in the present study clearly indicate that a gradual increase in the soluble protein content of turmeric leaves when they were treated with homobrassinolide (Table 3). Among the four different HBL concentrations used in the study 3.0 $\mu \mathrm{M}$ HBL was found to be marginally ahead of the other three concentrations $(0.5 \mu \mathrm{M} \mathrm{HBL}, 1.0 \mu \mathrm{M}$ HBL and $2.0 \mu \mathrm{M} \mathrm{HBL}$ ) in accounting increments in soluble protein levels. All the other treatments also accounted for good improvement of soluble proteins as compared to that of untreated plants.

\section{Discussion}

\subsection{Homobrassinolide and Chlorophylls in Turmeric Leaves}

The present study also revealed that foliar application of four concentrations $(0.5 \mu \mathrm{M} \mathrm{HBL}, 1.0 \mu \mathrm{M} \mathrm{HBL}, 2.0 \mu \mathrm{M}$ HBL and $3.0 \mu \mathrm{M} \mathrm{HBL}$ ) to turmeric plants promoted the levels chlorophylls in terms of chlorophyll 'a', chlorophyll 'b' and total chlorophylls. In earlier studies, application of brassinosteroids resulted in reducing the rate of chlorophyll degradation and the proteins associated with the chlorophylls, particularly proteins of light harvesting complexes in chloroplast thylakoid membranes [16]. The enhancement in the content of the chlorophylls under the impact of brassinosteroids could have possibly led to the improvement of light-capturing efficiency which might have resulted in higher photosynthetic rate manifested in terms of improved plant fresh mass and growth under stress conditions. Janeczko et al. [17] reported that treatments with brassinosteroid - 27 increased the carotenoid content grown at $2^{\circ} \mathrm{C}$ in rape leaves.

\subsection{Homobrassinolide and Carbohydrates in Turmeric Leaves}

The examination of starch part would give an insight on the commitment of sugars in plant development during trehalose treatment [18]. Yu et al. [19] revealed that use of 24-epibrassinolide essentially expanded in RUBISCO action and in the sucrose, solvent sugars and, starch substance pursued by significant increments in sucrose phosphate synthase, sucrose synthase and, corrosive invertase in cucumber plants developed in a nursery. Upgrade of photosynthetic rate with raised sugar amassing in coleus was seen by Swamy and Rao [20]. Vardhini and Rao, [8] reported enhanced reducing, non-reducing sugars and starch levels after Arachis hypogaea plant was sprayed with 24epibrassinolide and brassinolide. Foliar utilization of 24-epibrassinolide expanded the all-out solvent sugars in wheat cv. Tokra plants [21]. 


\subsection{Homobrassinolide and Soluble Proteins in Turmeric Leaves}

24-EpiBL, at concentrations of 10-7 M and 0.5 × 10-9 M mitigated the inhibitory effect of salinity in plants of Cajanus cajan (L.) Mill sp., cultivar C11 by increasing the levels of proteins, amino acids, nitrate, nitrate reductase of roots and the composition of xylem sap amino acids in the shoots.[22] The growth promotion in groundnut by BRs was found to be associated with improved nitrogen fixation [23] and soluble protein content [8]. Further, Arora et al. [24] observed that application of 24-epiBL enhanced growth, protein content and antioxidative defense system of Brassica juncea L. subjected to cobalt ion toxicity. Further, Sasse [25] also suggested that brassinosteroids have the ability to stimulate the synthesis of particular proteins associated with growth which is in tune with the present study where HBL increased chlorophyll pigments, carbohydrates and soluble proteins compared to the other treatments as well as control plants grown in saline soils of Nizamabad District.

\section{Conclusion}

The present research clearly depicts the stress alleviation nature of HBL which is a potent PGR. Application of HBL to turmeric plants resulted in alleviating the inhibitory effect of the semi-arid soils of Nizamabad and increased the chlorophylls, carbohydrates and soluble proteins in the plants. The increase in chlorophylls might have resulted in enhanced photosynthetic capability which in turn might have enhanced the carbohydrates and soluble proteins in turmeric plants.

\section{Compliance with ethical standards}

\section{Acknowledgments}

The authors acknowledge the critical review of Prof. S. Seeta Ram Rao, Osmania University, Hyderabad, TS, India.

\section{Disclosure of conflict of interest}

The corresponding author is the research guide of first author.

\section{References}

[1] Peleg Z, Blumwald E. Hormone balance and abiotic stress tolerance in crop plants. Current Opinion in Plant Biology. 2011; 14: 290-295.

[2] Ha S, Vankova R, Yamaguchi-Shinozaki K, Shinozaki K, Tran LS. Cytokinins: metabolism and function in plant adaptation to environmental stresses. Trends in Plant Science. 2012; 17:172-179.

[3] Rao SSR, Vardhini BV, Sujatha E, Anuradha S. Brassinosteroids a new class of phytohormones. Current Science. 2002; 82: 1239-1245.

[4] Mitchell JW, Mandava N, Worley JF, Plimmer JR, Smith MV. Brassins-a new family of plant hormones from rape pollen. Nature. 1970; 225:1065-1066.

[5] Bajguz A, Hayat S. Effects of brassinosteroids on the plant responses to environmental stresses: a review. Plant Physiology and Biochemistry. 2009; 47:1-8.

[6] Vardhini BV, Anuradha S, Sujata E, Rao SSR. Role of Brassinosteroids in alleviating various abiotic and biotic stresses-A Review. Plant Stress. 2010; 4: 55-61.

[7] Vardhini BV. Does application of brassinosteroids mitigate the temperature stress in plants?- A review. International Journal of Earth Science and Geology. 2019; 1(2):59-65.

[8] Vardhini BV, Rao SSR. Amelioration of osmotic stress by brassinosteroids on seed germination and seedling growth of three varieties of sorghum. Plant Growth Regulation. 2003; 41: 25-31.

[9] Vardhini BV, Rao SSR. Effect of brassinosteroids on growth, metabolite content and yield of Arachis hypogaea. Phytochemistry. 1998; 48: 927-930.

[10] Arnon DI. Copper enzymes in isolated chloroplasts. Polyphenol oxidase in Beta vulgaris. Plant Physiology. 1949; $24: 1-1$.

[11] Nelson N. A photometric adaptation of the Somogyi method for the determination of glucose. Journal of Biological Chemistry. 1944; 154: 375-380. 
[12] Loomis WE, Shull CA. Methods in Plant Physiology. Methods in Plant Physiology. A laboratory manual and research handbook. 1957.

[13] Yoshida S. Determination of sugar and starch in plant tissue. Laboratory manual for physiological studies of rice. 1976.

[14] Mc Cready RM, Guggloz J, Silveria V and Owens HS. Determination of starch and amylase in vegetables. Application to peas. Analytical Chemistry. 1950; 29: 1156-1158.

[15] Lowry OH, Rosenbrough NJ, Farr A, Randall RJ. Protein measurement with the Folin phenol reagent. Journal of Biological Chemistry. 1951; 193:265-75.

[16] Holá D. Brassinosteroids and photosynthesis. In: Hayat S, Ahmad S. (Editors). Brassinosteroids: a class of plant hormone. Springer, Netherlands. 2011; 143-192.

[17] Janeczko A, Gullner G, Skoczowski A, Dubert F, Barna B. Effects of brassinosteroid infiltration prior to cold treatment on ion leakage and pigment contents in rape leaves. Biologia Plantarum. 2007; 51: 355-358.

[18] Crowe JH, Crowe LM, Chapman D. Preservation of membranes in anhydrobiotic organisms: the role of trehalose. Science. 1984; 17: 223(4637): 701-3.

[19] Yu JQ, Huang LF, Hu WH, Zhou YH, Mao WH, Ye SF, Noques S. A role for brassinosteroids in the regulation of photosynthesis in Cucumis sativus. Journal of Experimental Botany. 2004; 55: 1135-1143.

[20] Swamy KN, Rao SSR. Effect of 24-epibrassinolide on growth, photosynthesis and essential oil content of Pelargonium graveolens L. Herit. Russian Journal of Plant Physiology. 2009; 56: 682-687.

[21] Janeczko J, Biesaga-Kościelniak J, Oklešt'ková M, Filek M, Dziurka G, Szarek- Łukaszewska J, Kościelniak. Role of 24-Epibrassinolide in Wheat Production: Physiological Effects and Uptake. Journal of Agronomy and Crop Science. 2010; 196(4): 311-321.

[22] Dalio RJD, Pinheiro HP, Sodek L, Haddad CRB. 24-Epibrassinolide restores nitrogen metabolism of pigeon pea under saline stress. Botanical Studies. 2013; 54: 9.

[23] Vardhini BV, Rao SSR. Effect of brassinosteroids on nodulation and nitrogenase activity in groundnut (Arachis hypogaea L.). Plant Growth Regulation. 1999; 28: 165-167.

[24] Arora N, Bhardwaj R, Kanwar MK. Effect of 24epibrassinolide on growth, protein content and antioxidative defense system of Brassica juncea L. subjected to cobalt ion toxicity. Acta Physiologia Plantarum. 2012; 34: 20072017.

[25] Sasse J. In: Sakurai A, Yokota T. Clouse SD (Editors). Physiological actions of brassinosteroids, Brassinosteroids: Steroidal Plant Hormones. Springer - Verlag, Tokyo, Japan. 1999; 151-153.a 